
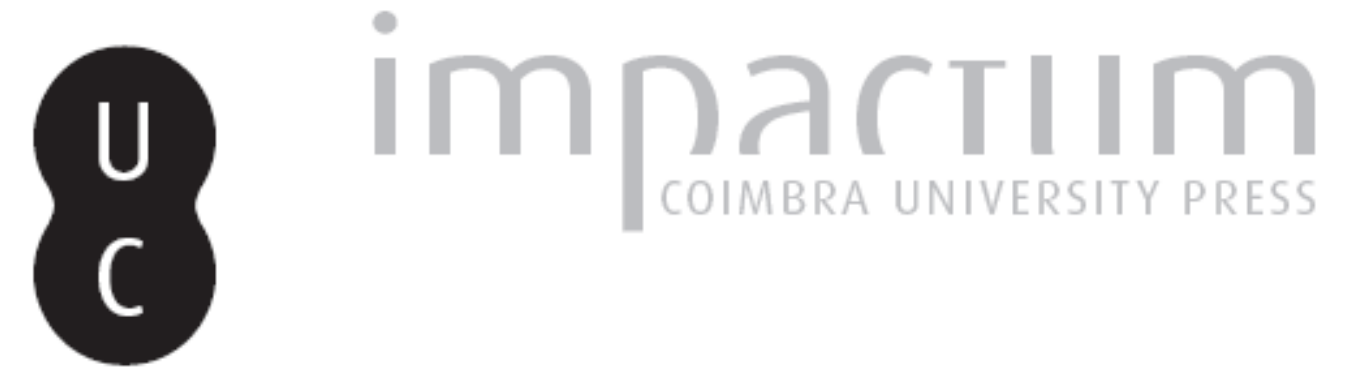

\title{
CIL, II, 2634: a posição político-religiosa de Q. Mamilius Capitolinus
}

\author{
Autor(es): Dias, Maria Manuela Alves
}

Publicado por: Imprensa da Universidade de Coimbra

URL persistente:

URl:http://hdl.handle.net/10316.2/45618

DOI:

DOI:https://dx.doi.org/10.14195/1647-8657_25_12

Accessed : $\quad$ 26-Apr-2023 10:05:41

A navegação consulta e descarregamento dos títulos inseridos nas Bibliotecas Digitais UC Digitalis, UC Pombalina e UC Impactum, pressupõem a aceitação plena e sem reservas dos Termos e Condições de Uso destas Bibliotecas Digitais, disponíveis em https://digitalis.uc.pt/pt-pt/termos.

Conforme exposto nos referidos Termos e Condições de Uso, o descarregamento de títulos de acesso restrito requer uma licença válida de autorização devendo o utilizador aceder ao(s) documento(s) a partir de um endereço de IP da instituição detentora da supramencionada licença.

Ao utilizador é apenas permitido o descarregamento para uso pessoal, pelo que o emprego do(s) título(s) descarregado(s) para outro fim, designadamente comercial, carece de autorização do respetivo autor ou editor da obra.

Na medida em que todas as obras da UC Digitalis se encontram protegidas pelo Código do Direito de Autor e Direitos Conexos e demais legislação aplicável, toda a cópia, parcial ou total, deste documento, nos casos em que é legalmente admitida, deverá conter ou fazer-se acompanhar por este aviso.

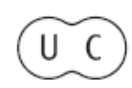


FACULDADE DE LETRAS

INSTITUTO DE ARQUEOLOGIA

CONIMBRIGA

$V O L U M E X X V$

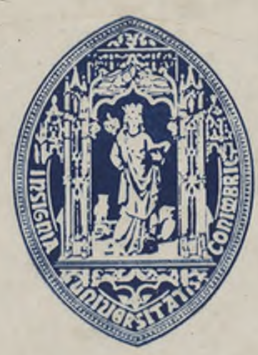

UNIVERSIDADE DE COIMBRA

1986 
Maria Manuela Alves Dias

Assistente da Faculdade de Letras de Lisboa.

CIL, II, 2634: A POSIÇÃO POLÍTICO-RELIGIOSA DE Q. MAMILIUS

CAPITOLINUS

«Conimbriga», XXV (1986), p. 193-203

Resumo : O texto de CIL, II, 2634 tem sido entendido como o cursus honorum de Q. Mamilius Capitolinus expresso numa invocatoria feita a quatro divindades, Júpiter, Sol, Liber Pater e o Génio do Pretório sem que, alguma vez, tenha sido feita uma leitura histórica interpretando o conjunto das referências desta inscrição. Intenta-se, agora, essa mesma leitura, aliás, historicamente óbvia.

RÉSUMÉ: L'inscription CIL, II, 2634, d'Astorga, associe le cursus honorum chevalier de Q. Mamilius Capitolinus à l'hommage rendue à Iupiter Optimus Mamimus, Sol invictus, Liber Pater et le Genius praetorii. L'A., dans ce petit article, établit la cohérence historique du cursus de Capitolinus avec l'assemblage de ces dieux et divinités. 
(Página deixada propositadamente em branco) 


\section{CIL, II, 2634: A POSIÇÃO POLÍTICO-RELIGIOSA DE Q. MAMILIUS CAPITOLINUS}

Depois da violenta morte de Cómodo, do curtíssimo reinado de Pértinax e do assassinato de Dídio Juliano em 193, era clara, como se sabe, a situação de confronto entre os chefes militares dos exércitos do Danúbio, do Oriente e do Ocidente, e, naturalmente, a escalada para o poder político admitia apenas um único vencedor; o estado de guerra civil era, assim, inevitável. Aquele que viria a triunfar, o imperador Lúcio Septimio Severo, fase a fase do seu percurso de conquista do poder absoluto, apercebeu-se da necessidade não só de legitimar-se socialmente pelo prestígio militar, mas também, e sobretudo, de dar aos Romanos urna imagem política que lhes garantisse que o processo de mudança dinástica, consigo iniciado, aparecesse como suficientemente justificado, sancionando toda e qualquer inovação real ou aparente; deste modo encetou práticas de propaganda política em que recuperou, em seu proveito, muitos elementos ou motivos conhecidos já sob os Antoninos. Sabe-se também que o quadro geográfico dos conflitos político-militares pela conquista do poder teve a dimensão do próprio Império, e cada província, mesmo quase cada cidade, participou neles, tomando partido por esta ou aquela facção político-oligárquica, consoante $\mathrm{o}$ peso das clientelas pessoais e os interesses das elites locais.

$\mathrm{Na}$ Hispânia, além dos históricos episódios militares, contados pelos autores clássicos $(* \bullet)$, que envolveram os partidários de Clódio

fi) Cf. v.g., SHA, Aer. Spartian., Severus, 12.1, 13.7 e Ceuleneer, A. d.e, Essai sur la vie et le règne de Septime Sévère, Liège, 1874, p. 56 e ss., Plautnauer, Maurice, The Life and Reign of the Emperor Lucius Septimius 
Albino e de Septimio Severo, assinalam-se alguns vestígios epigráficos que reflectem, indirectamente, o cuidado que Septimio tinha tido em fazer acompanhar a sua progressão política por um enquadramento ideológico-religioso conveniente à consolidação da sua posição e à estruturação dos seus propósitos e no qual se observava uma harmoniosa articulação dos vários componentes: os da tradição dinástica anterior, os seus próprios e, ainda, os da sua tradição familiar. Um dos referidos vestígios epigráficos é a inscrição votiva, proveniente de Astorga, CIL, II, $2634 \quad(=I L S$, 2299 - $C l M R M, 804)$ :

(signia militaria tria,

mediae lunae duae),

I(ovi) O(ptimo) M(aximo),

Soli invicto, Libero

patri, Genio praetor(ii),

Q(uintus) Mamil(ius) Capitolinus,

5 iurid(icus) per Flaminiam

et Umbriam et Picenum,

leg(atus) Aug(usti) per Asturiam et

Gallaeciam, dux leg(ionis) VII g(eminae) p(iae) fe[l(icis)],

praef(ectus) aer(arii) Sat(urni), pro salute

10 sua et suorum.

Quinto Mamilio Capitolino, ainda quando leg(atus) Aug(usti), ou muito pouco depois de ter cumprido este cargo, foi nomeado, por Septimio Severo, dux leg(ionis) VII g(eminae), em 197, para, na Hispânia, combater as forças dos partidários de Clódio Albino,

Severus, London, 1918, p. 97-113, Налеввоек, J., Untersuchungen zur Geschichte des Kaisers Septimius Severus, Heidelberg, 1921, p. 26 e ss., Birley, Anthony, Septimius Severus, the African Emperor, London, 1971, p. 65-170.

Abreviaturas usadas neste artigo: $B M C=$ Coins of the Roman Empire in the British Museum; CIL - Corpus Inscriptionum Latinarum; CIMRM = $=$ Corpus Inscriptionum et Monumentorum Religionis Mithriacae; ILS = - Inscriptiones Latinae Selectae; PIR - Prosopographia Imperii Romani; SHA $=$ Scriptores Historiae Augustae. 
tarefa que levou a bom termo e que lhe terá valido, como prémio, a nomeação para o cargo de praef(ectus) aer(arii) Sat(urni), (mencionado nesta inscrição votiva, feita pro salute sua et suorom e, talvez, mandada abrir nas vésperas da sua partida para Roma), cargo este que teria sido exercido por volta de $200\left(^{2}\right)$. Trata-se de um inequívoco partidário de Septimio Severo; os historiadores que analisaram a sua carreira são unânimes em defini-lo como um homem da total confiança do imperador ( ${ }^{3}$ ); admite-se mesmo que Quinto Mamilio Capitolino tenha ascendido da carreira equestre à senatorial por adlectio inter praetorios e que a sua nomeação para a chefia do aerarium Saturni seria um meio de lhe possibilitar o acesso até ao cargo de consul suffectus, a coroar a sua continuada fidelidade política e o seu sucesso militar na Hispânia ( $\left.{ }^{4}\right)$. Deste notável 'homem de mão' de Septimio Severo outra coisa não seria de esperar senão uma completa sintonia política e ideológica com a acção do imperador. Assim, nesta inscrição de Astorga, é bem evidente a coerência política e ideológica do conjunto das divindades invocadas: Iupiter Optimus Maximus ( $\left.{ }^{5}\right)$, Sol invictus, Liber pater, Genius praetorii que são algumas das que aparecem na propaganda monetária de Septimio contemporânea do conflito armado na Hispânia, claramente relacionáveis com esta situação política muito concreta e, sobretudo, com a necessidade de funda-

(2) Conв ie R, Mireille, IJaerarium Saturni et Vaerarium militare, Roma, 1974, p. 301.

${ }^{3}$ ) Alfóldy, Géza, Septimius Severus und der Senat, «Bonner Jahrbucher», 168, Bonn, 1968, p. 146, ID., Fasti Hispanienses, Wiesbaden, 1969, p. 90-92, ID., Die Senatorischen Kommandeure der Legio VII Gemina, "Legio VII Gemina», León, 1970, p. 390-391, Corbier, M., /. c., p. 301-303, LE Roux, Patrick, Varmée romaine et Vorganisation des provinces ibériques d'Auguste à Vinvasion de 409, Paris, 1982, p. 366-369; cf. tb. PIR', M-94; v. tb. genericam., v. g., Mac Mullen, Ramsay, Soldier and civilian in the later Roman Empire, Cambridge, Mass., 1967, p. 154-155.

$\left(^{4}\right)$ Corbier, M., 1. c., p. 536; sobre adlectus ou allectus ef. Cagnat, René, Cours d?épigraphie latine, 4èine éd., Paris, 1914, p. 126.

(5) Para este culto na Península cf. Peeters, Félix, Le culte de Jupiter en Espagne d'aprés les inscriptions, «Revue Beige de Philologie et d'Histoire», Bruxelles, 1938, p. 157-191 e 853-886. Cf. tb. VAzquez y Hoys, Ana Maria, Consideraciones estadísticas sobre la religión romana en Hispânia, «La religión romana en Hispânia», Madrid, 1981, p. 165-176, especialm. 168-169 e ID., La religión romana en Hispânia, Madrid, 1982. 
mentação ideológico-religiosa do poder e da sua legitimação $\left(^{6}\right)$.

Esta sequência de divindades, tal como aparece, respeita uma ordem de grandeza decrescente, da mais universal à mais particular; segue-se-lhe o nome de Q. Mamilio Capitolino, naturalmente sem qualquer referência à filiação e à tribo, e os sucessivos cargos da sua carreira de eques, numa ordem ascendente e cronológica. Vejamos a sequência do conjunto das divindades invocadas:

Iupiter Optimus Maximus é aqui, ainda, o deus supremo, o deus-chefe, preferencialmente cultuado pelos militares (a reforçar esta ideia estão os signa militaria que encimavam o altar da inscrição), na continuidade de uma prática castrense que tinha readquirido especial relevo sob Trajano $\left.{ }^{7}\right)$, deus máximo da tríade capitolina que acompanhava e favorecia as conquistas e que era, pelas suas características polimorfizáveis, suficientemente universal para o fazerem tomar os epítetos de divindades supremas locais ou, até, de se lhes associar $\left(^{8}\right)$. Não foi nesta conjuntura, nem ainda nesta época, que rivalizou com o Sol invictus $\left({ }^{9}\right)$; efectivamente, um pouco mais tarde, sob Heliogábalo (218-222), Iupiter Optimus Maximus quase que constituiu, como expressão de resistência da longa-duração ideológica-religiosa, uma verdadeira ameaça à nova hegemonia religiosa do culto solar sírio de Emesa, e foi por vontade deste imperador que foi proibida, na prática religiosa e nas menções epigráficas, a sua nomeação antes da de Sol invictus - enfim, um caso de precedência na pragmática do cerimonial religioso privado e oficial, alterada e imposta pela vontade política do poder absoluto.

(6) BMC, V, p. LXXXII-CXCI. Sobre vários aspectos da arte e do espectacular, na propaganda política de Septimio Severo, cf. tb. o. g., 1 оулвев, J. M. C., Picture-Language in Roman Art and Coinage, «Essays in Roman Coinage presented to Harold Mattingly», Oxford, 1956, p. 205-225. Completando BMC, V, v. HıLl, Philip V., The coinage of Septimius Severus and his family of the Mint of Borne, A.D., 193-217, London, 1964.

(7) B $\mathrm{EAuje}_{\mathrm{u}}$, Jean, La religion romaine à Vapogée de VEmpire, Paris, 1955, p. 69-80.

(8) Peeters, F., 1. c., p. 185-187 e 853-873.

(') Halsmerche, Gaston H., The Cult of Sol Invictus, Leiden, 1972, p. 62 e $75-76$. 
Sol invictus, a segunda divindade mencionada nesta inscrição $\left({ }^{10}\right)$, à data da invocatoria de Q. Mamilio Capitolino, só poderá ser entendido como referência do apelo a uma ordem cósmica que comanda o Mundo e guia, do Alto, as acções do imperador, tal como vai aparecer na imagem do Septizonium, mandado edificar por Septimio em 202 (u); a ideologia dinástica, cósmicamente sustentada, foi sobretudo o resultado de um processo de aceleração dum movimento que tinha já antecedentes em Roma, e que não terá necessariamente nada a ver com a origem oriental de Iulia Domna, a segunda mulher de Septimio Severo (12). As duas meias-luas que, tal como os signa militaria, encimavam o altar da inscrição devem ser entendidas como indiciadoras da referida ordem cósmica (13); símbolos solares e lunares, representados em

(10) ID., ibid., não inclui CIL, II, 2634 talvez por lhe atribuir carácter mitraico, seguindo assim CIMRM, 804 que a não tem sob reserva; contudo Garcia y Bellido, António, Les religions orientales dans VEspagne romaine, Leiden, 1967, p. 37-38, diz textualmente: «II n'est pas sur que le texte de cette pierre soit mithriaque».

(") Номо, Léon, Rome impériale et Vurbanisme dans VAntiquité, Paris,

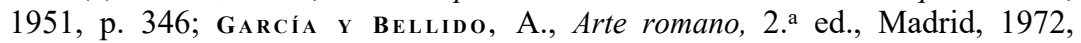
p. 530-533, escreve: «...el Septizonium, ruina bien conservada aún hasta finales del siglo xvi. Sisto V la mandó demoler con el fin de utilizar sus ricos materiales para obras suyas. Son varios, empero, los dibujos que de este monumento nos han llegado; uno de ellos es el conservado hoy en el Escorial, debido a Francisco de Holanda». Y. tb. Lugli, Giuseppe, Le Palatin, Roma, 1949, p. 139-141.

(12) GAGÉ, Jean, «Rasiléia»: Les césars, les rois d'Orient et les miages», Paris, 1968, p. 235-236: «Étant donné l'origine émésienne et sacerdotale de Julia Domna, Pimpératrice, il était tentant naguére de considérer que ces symboles, et ces nouveautés d'architecture méme, étaient entrés au Palatin avec le couple afro-syrien. Mais de nouvelles découvertes, notamment celles d'un Septizodium en Tunisie' (Gilaert-Charles Picard, Le Septizodium de Cincari et le probléme des Septizonia, «Monuments Piot», 522, Paris, 1962, p. 77-94), ont prouvé qu'il n'y avait pas eu brusque invention ni admission de ces symboles astraux pour Septime-Sevère; seulement une accélération dans un mouvement qui avait commencé hors de Rome, et mise en forme naturellement exploitée pour Pavenir d'une maison qui, dés le début, s'annonçait dynastie». Documentação arqueológica (incluindo a numismática) relativa a esta problemática em GHedini, Francesca, Giulia Domna tra Oriente e Occidente, Roma, 1984.

(13) SEYRIG, Henri, Le prétendu syncrétisme solaire syrien et le cuite de Sol invictus, «Les syncrétismes dans les réligions grecque et romaine», Paris, 
associação com os membros da casa imperial (ou como aparente emblemática pessoal), são motivos inseridos na propaganda monetária da predestinação dinástica da família reinante — a sugestão é clara na representação dos bustos conjugados de L. Septimius Severus e Iulia Domna, com coroa radiada e sobre crescente, respectivamente, rodeados pela legenda Concordiae aeternae (14). Esta mesma ideia aparece, na epigrafia, na invocatoria conjunta ao Sol eterno e à Lua, feita em intenção da eternidade do Império e da saúde do Imperador, de Iulia Domna e dos seus dois filhos (15). Também, no mesmo esforço de estratégia de implantação dinástica, já em 195, ano da sua vitória sobre Pescennius Niger, e quando Clódio Albino era o seu último obstáculo, Septimio Severo começou a autodenominar-se divi Marci filius e divi Commodi frater, no claro propósito de se 'entroncar' na familia de Marco Aurélio (note-se que a gens Aurelia era a que, tradicionalmente, mantinha, no Quirinal, o culto romano do $\operatorname{Sol}\left({ }^{16}\right)$, e, no ano seguinte, quando atribuiu ao seu filho mais velho, Septimius Bassianus, o futuro imperador Caracala, o título de Caesar, mudou-lhe o nome para M. Aurelius Antoninus (17); em 197, depois da derrota e morte de Clódio Albino, Caracala é nomeado já, na epigrafia, imperator designatus (18), iniciando na primavera do ano seguinte o reinado conjunto com seu pai (198-211). A usurpação da onomástica familiar dos Antoninos não foi a única perpetrada por Septimio. Já anteriormente, em 193, com a aprovação do Senado e quando

1973, p. 147-151. Cf. tb. Mac Mullen, Ramsay, Paganism in the Roman Empire, Yale, New Haven, 1981, p. 84-85.

(14) BMC, Y, p. 194 e 204. Cf. tb. Beaujeu, J., Politique religieuse et propagande numismatique sous le Haul-Empire, «Mélanges d'Archéologie et d'Histoire offerts à André Piganiol», Paris, 1966, p. 1529-1540 e Béranger, Jean, Remarques sur la Concordia dans la propagande monétaire impériale et la nature du principal, «Beitráge zur Alten Geschichte und deren Nacbleben. Festschrift für Franz Altheim zum 6.10.1968», Berlin, 1969, p. 477-491.

(15) Cf. CIL, II, 259, de Colares, Sintra.

(16) Halsberghe, G. H., 1. c., p. 35.

(17) Cf. SHA, Ael. Spartian., Severus, 10.6; BMC, Y, p. LXXIX e Syмe, Ronald, Emperors and Biography, London, 1971, p. 78-88. Na epigrafia hispânica cf. CIL, II, 1671, de Martos, na Bética.

(18) Cf. CIL, VIII, 14394 e CIL, II, 4101 (== Alfõldy, G., Die Rõmischen Inschriften von Tarraco, Berlin, 1975, p. 42, Taf. 16.2). 
chamava a si o privilégio da vingança de $P$. Helvius Pertinax, ligara ao seu próprio nome o cognome deste, numa evidente tentativa de vinculação sucessória $\left({ }^{19}\right)$.

Liber pater, identificável com Baco e, desde 194, um item quase constante da propaganda monetária de Septimio Severo $\left({ }^{20}\right)$, era um dos dois deuses mais prestigiados de Leptis Magna, a cidade natal do imperador e terá sido, para este, o deus propiciatório e tutelar das suas intenções e propósitos, tanto que, nos Ludi Saeculares de 204, lhe prestou honras especiais (21).

Genius praetorii, a última divindade invocada, aparece na Hispânia também representada epigráficamente em Tarragona (22), numa inscrição com uma invocatoria que começa pela tríade Capitolina e que foi mandada fazer por T. Flavius Titianus, governador da Hispania Citerior (199-202), cunhado do desaparecido Pertinax e, tal como Q. Mamilio Capitolino, igualmente um fervoroso partidário de Septimio Severo $\mathrm{p}$ ); trata-se, pois, duma divindade castrense que se harmoniza bem com o estado de guerra civil que se vivera na Península, com a classe militar ascendente e, até, com as biografias quer do imperador quer de Q. Mamilio Capitolino e de T. Flávio Ticiano $\left({ }^{24}\right)$.

(19) Cf. SHA, Ael. Spartian., Severus, 5.4 e SHA, Iul. Capítol., Pertinax, 15.2.

${ }^{(20)} B M C, \mathrm{~V}, \mathrm{p} . \mathrm{LXXXVII.}$

(21) Cf., v. g., Cass. Dio, 77.16 e $B M C$, Y, p. XL.

(22) CIL, II, 4076, (Genius praetorii consularis).

(23) Alfoldy, G., Septimius Severus..., p. 142 e ID., 1. c. n. 18, p. 18, Taf. 62.3. V. tb. $P I B^{2}$, F-387.

(24) Sob Septimio, uma emergente classe militar, muito fiel e cujos membros eram geralmente de origem provincial africana, ou síria, apoiou e sustentou politicamente o imperador na execução da sua fórmula 'descaramente' autocrática de exercício do Poder. Crees, J. H. E., The Beign of the Emperor Prohus, London, 1911, p. 5, escreve: «The reign of Severus (A. D. 193-211) has rightly been said (STuART Jones, The Boman Empire, p. 252) to mark an epoch in the history of autocracy. The imperial power was based henceforth upon the army, and upon the army alone, and the fiction of the dyarchy, a partnership between Emperor and Senate, was allowed to fall into oblivion. The soldier, who became such an important personage, was pampered and allowed to disregard the claims of discipline. He lived in plenty and in the bosom of his family (restrictions upon marriage 
A informação religiosa e a informação prosopográfica dadas pela inscrição CIL, II, 2634, formam um todo que tem uma coerência interna que as torna inseparáveis.

Os deuses invocados, nesta inscrição de Astorga, por Q. Mamilio Capitolino são aqueles que um oficial, nas suas circunstâncias de carreira, à data e no seu alinhamento político, preferencialmente escolheria para uma inscrição deste tipo, no ocidente do Império; hipoteticamente, e por um senso comum cautelar, podemos ainda considerar que Q. Mamilio Capitolino, ao invocar os deuses 'de' Septimio Severo, não estava a fazer propaganda directa da política religiosa do imperador mas, sim, a fazer a sua própria profissão-de-fé político-ideológica; de facto, era também admissível que, para quem construiu uma carreira na luta contra os opositores de Septimio Severo, encontrasse, nos deuses invocados durante essa luta, a protecção que, privadamente, requer para si e para os seus; ora isto não impediria, fosse como fosse, que a inscrição, como objecto público, não resultasse, indirectamente, num poderoso elemento activo da propaganda ideológico-religiosa da política do imperador e que se iria reflectir, mesmo minimamente, no comportamento político dos círculos dos graduados militares de Astorga e da legio e das elites civis locais (20̃).

were now abolished, legionaries wore gold rings and received frequent donatives). The rest of the world under this rule of militarism became mere ciphers. (...) The Senate dared not oppose the slightest wish of its imperial master, and lost most of its revenues, owing to the reduction of the aerarium to insignificance». Esta 'leitura' da moderna historiografia liberal e democrática subsiste em autores bem diferençados ideologicamente como J. Beaujeu ou Levi, Mario Attilio, La lucha política en el mundo antiguo, trad. esp. da ed. i tal. de 1955, Madrid, 1968, p. 282-283, que consideram, directa ou indirectamente, o reinado 'militarista' de Septimio como o marco inicial da decadencia do império - mesmo o vigoroso surto de construções, públicas e privadas, as reformas viárias, o discurso político de contenção social, a 'conquista' da Mesopotamia, etc., (só possíveis pela duração do poder pessoal do imperador e pela sua equilibrada administração da guerra nas fronteiras do Império que, ao fim e ao cabo, se conservam tal qual) acabam por ser entendidos como expressão de hábil 'fachadismo' político, inconsistente e incapaz de, ao menos, desacelerar o processo de decadência.

(25) Cremos, firmemente, que, quando o séc. II acaba, já se está, socialmente, a nivel provincial, muito distante da 'apatia política' que, há muito, 
Como se vê, a inscrição C7L, II, 2634, não pode ser reduzida, a nível informativo, de conhecimento e de significado, a um somatório do enunciado de quatro divindades (26) e de um cursus honorum 'equestre' dum homo novus da entourage militar de Septimio Severo: ela é um todo coerente, historicamente inteligível.

numa obra magnífica, se diagnosticou no comportamento das élites locais, itálicas e provinciais, sob os Júlio-Gláudios: воглsгев, Gaston, Vopposition sous les Césars, Paris, 1875, p. 18-55.

(26) Sobretudo se forem entendidas como expressão dum sincretismo religioso, veiculado pelas unidades militares. éтпеме, Robert, Les syncrétismes religieux dans la Péninsule Ibérique à Vépoque impériale, «Les syncrétismes...», p. 161, a propósito desta inscrição e do papel dos militares, considera com inteligente subtileza: «mais il ne faut pas exagérer leur importance pas plus que Pefficacité de la propagande officielle». 